\title{
Determinants of repeated abortion among women of reproductive age attending health facilities in Northern Ethiopia: a case-control study
}

Mussie Alemayehu ${ }^{1 *}$ D, Henock Yebyo ${ }^{1}$, Araya Abrha Medhanyie ${ }^{1}$, Alemayehu Bayray ${ }^{1}$, Misganaw Fantahun ${ }^{2}$ and Gelila Kidane Goba ${ }^{3}$

\begin{abstract}
Background: Every year, an estimated 19-20 million unsafe abortions take place, almost all in developing countries, leading to 68,000 deaths and millions more injured many permanently. Many women throughout the world, experience more than one abortion in their lifetimes. Repeat abortion is an indicator of the larger problem of unintended pregnancy. This study aimed to identify determinants of repeat abortion in Tigray Region, Ethiopia.

Methods: Unmatched case-control study was conducted in hospitals in Tigray Region, northern Ethiopia, from November 2014 to June 2015. The sample included 105 cases and 204 controls, recruited from among women seeking abortion care at public hospitals. Clients having two or more abortions ("repeat abortion") were taken as cases and those who had a total of one abortion were taken as controls ("single abortion"). Cases were selected consecutive based on proportional to size allocation while systematic sampling was employed for controls. Data were analyzed using SPSS version 20.0. Binary and multiple variable logistic regression analyses were calculated with $95 \% \mathrm{Cl}$.

Results: Mean age of cases was 24 years $( \pm 6.85)$ and 22 years $( \pm 6.25)$ for controls. $79.0 \%$ of cases had their sexual debut in less than 18 years of age compared to $57 \%$ of controls. $42.2 \%$ of controls and $23.8 \%$ of cases cited rape as the reason for having an abortion. Study participants who did not understand their fertility cycle and when they were most likely to conceive after menstruation (adjusted odds ratio $[A O R]=2.0,95 \%$ confidence interval [Cl]: 1.1-3.7), having a previous abortion using medication ( $\mathrm{AOR}=3.3, \mathrm{Cl}$ : 1.83, 6.11), having multiple sexual partners in the preceding 12 months ( $A O R=4.4, C l: 2.39,8.45$ ), perceiving that the abortion procedure is not painful ( $A O R=2.3, \mathrm{Cl}: 1.31,4.26)$, initiating sexual intercourse before the age of 18 years $(A O R=2.7, C l: 1.49,5.23)$ and disclosure to a third-party about terminating the pregnancy $(A O R=2.1$, Cl: 1.2,3.83) were independent predictors of repeat abortion.

Conclusion: This study identified several factors correlated with women having repeat abortions. It may be helpful for the Government of Ethiopia to encourage women to delay sexual debut and decrease their number of sexual partners, including by promoting discussion within families about sexuality, to decrease the occurrence of repeated abortion.
\end{abstract}

Keywords: Abortion, Single abortion, Repeated abortion, Tigray, Ethiopia

\footnotetext{
* Correspondence: mossalex75@gmail.com

'School of Public Health, Mekelle University, College of Health Sciences,

Mekelle, Ethiopia

Full list of author information is available at the end of the article
} 


\section{Background}

Globally, unsafe abortion is the leading cause of death among pregnant women and causes $13 \%$ of all maternal deaths [1]. In developing countries, a woman dies every 8 min due to complications arising from unsafe abortion. An estimated 10-50\% of women face life-threatening complications and long-term consequences such as incomplete abortion, infection and secondary infertility due to abortion [2-4]. Even among women for whom abortion is induced, approximately $10 \%$ experience immediate complications, of which one-fifth are considered major $[5,6]$. Providing post-abortion service is a widely accepted public health strategy to reduce maternal morbidity and mortality. Linking abortion care and comprehensive family planning can help prevent future unwanted pregnancies and repeat abortions [7-9].

A study in Mozambique showed that most postabortion clients (86\%) had a prior pregnancy and almost half (44\%) an abortion before the current one [10]. Repeat abortion is associated with many problems, including poor health [11]. Women who had one, two or more previous induced abortions are 1.89, 2.66 and 2.03 times more likely, respectively, to have a subsequent pre-term delivery, compared to women who carry to term. Prior induced abortion not only increases the risk of premature but also delayed delivery [12]. The risk of repeat abortion within the abortion population follows a bell-curve: $7.3 \%$ are adolescents, $30.8 \%$ are $30-34$ years old and $13.0 \%$ are above the age of 44 [13].

The magnitude of repeat abortion in Ethiopia is not known, which this study seeks to help illuminate. The overall prevalence of unintended pregnancy in Ethiopia is about $42 \%$. Out of an estimated 3.27 million pregnancies annually, 500,000 ends up in either spontaneous or unsafely induced abortion [8]. This study can help policymakers working in the area of maternal health to promote the well-being of mothers and women of reproductive age by identifying determinants of repeat abortion by testing the hypothesis "there was a difference in factors that determine for having abortion among women of reproductive age group in those with once abortion and having repeated abortion in terms of contraceptive use, client factors and health service related factors".

\section{Methods}

An unmatched case-control study was conducted in hospitals in Tigray Region, northern Ethiopia, from November 2014 to June 2015. The sample size was calculated by considering the proportion of contraceptive non-use among first-time (48.9\%) and repeat (30.9\%) abortion seekers as shown in other studies in Ethiopia [14]. It was calculated using Epi-info version 7. We used $95 \% \mathrm{CI}$ and $80 \%$ power of the test with a $1: 2$ ratio of cases to controls. A total sample size of 315 was determined, including105 cases and 210 controls, which also accounted for $10 \%$ non-response.

There are 16 governmental and two private hospitals as well as 256 health centers in Tigray [15]. From these 16 governmental hospitals, we randomly selected eight hospitals. In these hospitals, all clients 15-49 years of age who came for seeking post-abortion care for at least the second time were considered as cases ("repeat abortion"). Those seeking care following their first abortion were considered as controls ("single abortion"). First, the total sample size of both case and controls was proportionally allocated to the selected hospital based on their 3-month previous caseload. Then, to select controls, we used systematic sampling technique, but for cases, we enrolled all women (consecutive) until the required sample size was filled.

Data were collected using a structured questionnaire; administered in-person by 12 nurse interviewers experienced in abortion care and 4 health officers was deployed for supervision. Questionnaires included socio-demographic and economic variables, health and healthcare-related factors and knowledge about contraceptive use. Questionnaires were adapted from different literature and took into account the local context [16-18]. History of abortion either single or repeat abortion was identified from medical records of the patients. Besides, so as to minimize bias the patient was asked either the patient comes to seek abortion service for the first time or second and above. And the patient response was checked with the medical record. And in the case of inconsistent finding, the patient response was taken. The outcome variable of this study was an episode of abortion either single or repeat (two and more). Furthermore, in this study, "surgical abortion" includes abortion from manual vacuum aspiration (MVA) or curettage.

The questionnaire was prepared in English and translated to Tigrigna. It was checked for consistency by back-translation to English by two different individuals. The data collection process was strictly supervised and data was checked for consistency and completeness. Incomplete and unclear questionnaires were returned to interviewers to be completed.

\section{Data analysis}

Data were entered, cleaned and analyzed using SPSS 20 for Windows (SPSS Inc. Version 20, Chicago, Illinois). Data cleaning was done by running frequencies, crosstabulation and sorting among reported cases or variables. Frequency and mean were obtained for variables. A "binary analysis" was used to describe the association between independent and dependent variables and a multiple variable logistic regression analysis was used to show factors determining outcome variables. Before proceeding to the multivariable logistic regression, variables 
which had a $p$-value of 0.25 or less in the binary logistic regression were included in the multivariable logistic regression. Finally, $P$-value $<0.05$ was considered statistically significant for all independent variables at the multivariable logistic regression.

Crude odds ratio (COR) and adjusted odds ratio (AOR) were calculated. To determine the factors most statistically significantly associated with repeat abortion, odds ratio at $95 \%$ CI was determined using logistic regression analysis. The final model was fitted using the Hosmer-Lemeshow Goodness of Fit Test and multicollinearity were checked to minimize bias. The goodness of fit of the final model was checked by using the HosmerLemeshow Goodness of Fit Test and $p$-value greater than 0.05 considered as the model fit to the logistic regression. For the multicollinearity, we use Variance Inflator Factor (VIF) to the inquiry instability of the effect size of predictors as the result of high collinearity among themselves. The multicollinearity was checked by using mean, variance inflation factors (VIF) cutoff point of 10 .

\section{Results}

Socio-demographic characteristics of study participants

Of the 314 women who visited abortion clinics at selected hospitals during the study period, 309 completed the interview, a response rate of $98.4 \%$. And the main reason for non-response was a refusal to participate in to study. Among these, 105 (33.9\%) were cases ("repeat abortion") and 204 (66.1\%) controls ("single abortion"). The mean age of cases was 24 years ( $\operatorname{Min}=16, \operatorname{Max}=42$, $\mathrm{SD}=6.85)$ and 22 years $(\operatorname{Min}=15, \operatorname{Max}=42, \mathrm{SD}=6.25)$ for controls. The majority of subjects were from urban areas: $65.7 \%$ of cases and $75.5 \%$ for controls. Orthodox Christian and Tigrawot were the predominant religious and ethnic groups, respectively: $78.1 \%$ and $83.8 \%$ of cases were Orthodox Christian and Tigrawot, respectively, compared to $88.2 \%$ and $87.3 \%$, respectively, of controls. Nearly one-fourth $(24.8 \%)$ of cases and18.6\% of controls were unable to read and write. Just over $30 \%$ of cases had attended grades 9-12 compared to $37.6 \%$ of controls. Roughly half of cases and controls were married. Over $40 \%$ of controls were students and $35 \%$ of cases were employed. Approximately $60 \%$ of controls and cases did not have their own incomes (Table 1).

\section{Reproductive history of study participants}

Seventy-nine percent (79.0\%) of cases and $57.4 \%$ of controls had their first sexual intercourse before the age of 18 years. More than four-fifths (86.3\%) of controls had ever been pregnant previously. In terms of sexual partners, $46.6 \%$ of controls and $72.4 \%$ of cases had two or more sexual partners ever and $19.1 \%$ of cases and $41 \%$ of controls had two or more partners in the
Table 1 Socio demographic characteristics of the study respondents, Tigray region, 2015

\begin{tabular}{|c|c|c|c|c|}
\hline Variables & Controls & Cases & Total & $P$-Value \\
\hline & $N(\%)$ & $N(\%)$ & $N(\%)$ & \\
\hline \multicolumn{5}{|l|}{ Age } \\
\hline Less than 18 & 38 (18.6) & $10(9.5)$ & $48(15.5)$ & \multirow[t]{2}{*}{0.15} \\
\hline 18 and above & $166(81.4)$ & 95 (90.5) & $261(84.5)$ & \\
\hline \multicolumn{5}{|l|}{ Residence } \\
\hline Urban & $154(75.5)$ & $69(65.7)$ & $223(72.2)$ & \multirow[t]{2}{*}{0.049} \\
\hline Rural & $50(24.5)$ & $36(34.3)$ & $86(27.8)$ & \\
\hline \multicolumn{5}{|l|}{ Religion } \\
\hline Orthodox & $180(88.2)$ & $82(78.1)$ & $262(84.7)$ & \multirow[t]{2}{*}{0.006} \\
\hline Other ${ }^{a}$ & $24(11.8)$ & $23(21.9)$ & $47(15.3)$ & \\
\hline \multicolumn{5}{|l|}{ Ethnicity } \\
\hline Tigrawot & $178(87.3)$ & 88 (83.8) & $266(86.1)$ & \multirow[t]{2}{*}{0.39} \\
\hline Other ${ }^{b}$ & $26(12.7)$ & $17(16.2)$ & $43(13.9)$ & \\
\hline \multicolumn{5}{|l|}{ Educational status } \\
\hline Unable to read and write & $38(18.6)$ & $26(24.8)$ & $64(20.7)$ & \multirow[t]{5}{*}{0.41} \\
\hline Able to read and write & $21(10.3)$ & $10(9.5)$ & $31(10.0)$ & \\
\hline $1-8$ grade & $35(17.2)$ & $22(21.0)$ & $47(15.2)$ & \\
\hline 9-12 grade & $77(37.7)$ & $33(31.4)$ & $110(35.5)$ & \\
\hline College or university level & $33(16.2)$ & $14(13.3)$ & $47(15.2)$ & \\
\hline \multicolumn{5}{|l|}{ Marital status } \\
\hline Married & $81(39.7)$ & $55(52.4)$ & $136(44)$ & \multirow[t]{4}{*}{0.10} \\
\hline Single & $97(47.5)$ & $38(36.2)$ & $135(43.7)$ & \\
\hline Divorced & $21(10.3)$ & $12(11.4)$ & $33(10.7)$ & \\
\hline Widowed & $5(2.5)$ & - & $5(1.6)$ & \\
\hline \multicolumn{5}{|l|}{ Occupation } \\
\hline Students & $87(42.6)$ & $34(32.4)$ & $121(39.2)$ & \multirow[t]{3}{*}{0.10} \\
\hline Housewives & $50(24.5)$ & $34(32.4)$ & $84(27.2)$ & \\
\hline Employed & $67(32.8)$ & $37(35.2)$ & $104(33.7)$ & \\
\hline \multicolumn{5}{|l|}{ Had own income } \\
\hline Yes & $74(36.3)$ & $43(41.0)$ & $117(37.9)$ & \multirow[t]{2}{*}{0.53} \\
\hline No & $130(63.7)$ & $62(59.0)$ & $192(62.1)$ & \\
\hline
\end{tabular}

${ }^{\mathrm{a}}$ Muslim and protestant

${ }^{\mathrm{b}}$ Amhara and Oromo

12 months preceding the survey, respectively. As such, cases were approximately twice as likely to have had two or more sexual partners. Nearly $80 \%$ of controls and $67.6 \%$ of cases want to have children in the future (Table 2).

\section{Abortion-related characteristics of respondents}

Rape was the reason $42.2 \%$ of controls and $23.8 \%$ cases sought an abortion. A further $14.2 \%$ of controls and $13.3 \%$ of cases cited incest as the reason for seeking an abortion. In terms of a number of abortions, $87.6 \%$ of cases had two previous abortions while $10.5 \%$ and $1.9 \%$ had three and four or more previous abortions, 
Table 2 Reproductive history of the study respondents, Tigray region, 2015

\begin{tabular}{|c|c|c|c|c|}
\hline \multirow[t]{2}{*}{ Variables } & Controls & Cases & Total & \multirow[t]{2}{*}{ P-Value } \\
\hline & $N(\%)$ & $N(\%)$ & $N(\%)$ & \\
\hline \multicolumn{5}{|c|}{ Age at first sexual intercourse } \\
\hline Less than 18 & $117(57.4)$ & $83(79.0)$ & $200(64.7)$ & \multirow[t]{2}{*}{$<0.01$} \\
\hline 18 and above & $87(42.6)$ & $22(21.0)$ & $109(35.9)$ & \\
\hline \multicolumn{5}{|c|}{ Ever number of sexual partners } \\
\hline One & $109(53.4)$ & $29(27.6)$ & $138(44.7)$ & \multirow[t]{2}{*}{$<0.01$} \\
\hline Two and above & $95(46.6)$ & $76(72.4)$ & $171(55.3)$ & \\
\hline \multicolumn{5}{|c|}{ Number of sexual partners in the past 12 months } \\
\hline One & $165(80.9)$ & $62(59.0)$ & $227(73.5)$ & \multirow[t]{2}{*}{$<0.01$} \\
\hline Two and above & $39(19.1)$ & $43(41.0)$ & $82(26.5)$ & \\
\hline \multicolumn{5}{|c|}{ Ever been pregnant before } \\
\hline Yes & $176(86.3)$ & $105(100.0)$ & $281(90.9)$ & \multirow[t]{2}{*}{$<0.01$} \\
\hline No & $28(13.7)$ & - & $28(9.1)$ & \\
\hline \multicolumn{5}{|c|}{ Did want to have children for the future } \\
\hline Yes & $161(78.9)$ & $71(67.6)$ & $232(75.1)$ & \multirow[t]{2}{*}{0.05} \\
\hline No & $43(21.1)$ & $34(32.4)$ & $77(24.9)$ & \\
\hline
\end{tabular}

respectively. Most (78.4\%) controls and $52.4 \%$ of cases reported that the current abortion was done surgically. Over half, (54.9\%) of controls and $30.5 \%$ of cases indicated the abortion procedure was painful.

Fourteen percent (14.2\%) and $22.1 \%$ of controls and $13.3 \%$ and $18.1 \%$ of cases did not receive counseling about family planning or instruction on when to return to fertility after the abortion, respectively. A significant number of women had some complication while they were pregnant, including $21.1 \%$ of controls and $29.5 \%$ of cases. Bleeding was the most common complication and was experienced by $74.4 \%$ of controls and $80.6 \%$ of cases. Approximately, $30 \%$ of women in both groups faced psychological problems after the procedure.

Forty-four percent (44.1\%) of controls and $58.1 \%$ of cases disclosed to another individual about terminating the pregnancy. Majority (51.1\%) of controls and $44.3 \%$ of cases disclosed to their friends (Table 3).

\section{Health-related characteristics of respondents}

Two-thirds of controls and cases had ever used family planning. Of these, $59.4 \%$ of controls and $72.2 \%$ of cases had ever used injectable contraceptives. Emergency contraceptives were ever used by $38.3 \%$ of controls and $43.3 \%$ of cases. Among women who took an emergency contraceptive, a considerable percentage $-22.7 \%$ of controls and $50 \%$ of cases -had ever taken emergency contraceptives within 1 day of unprotected sexual intercourse. More than six in ten cases and controls thought that their menstrual flow was regular. Three-fourths of controls and $67.6 \%$ of cases thought that repeat abortion results in infertility (Table 4).

\section{Predictors of repeated abortion}

Adjusting for other variables, the odds of repeat abortion was 2.0 times with $(\mathrm{AOR}=2.0, \mathrm{CI}: 1.12,3.69)$ more likely with women who did not understand their fertility cycles and when they were most likely to conceive after menstruation as compared with their counterparts. And the odds of repeat abortion was 3.3 times with $(\mathrm{AOR}=3.3$, CI: $1.83,6.11$ ) more likely among women who previously used medication for an abortion procedure as compared women who had a surgical abortion procedure. The odds of repeat abortion was 4.4 times with $(\mathrm{AOR}=4.4, \mathrm{CI}$ : 2.39, 8.45) more likely among women who had multiple sexual partners in the past 12 months as compared to those who had one sexual partner. Besides, the odds of repeat abortion was 2.3 times with $(\mathrm{AOR}=2.3$, CI: $1.31,4.26)$ more likely among women who perceived that the abortion procedure was not painful as compared to those who thought that the procedure was painful. Furthermore, the odds of repeat abortion was 2.7 and 2.1 times with $(\mathrm{AOR}=2.7, \mathrm{CI}=1.49$, 5.23) and (AOR $=2.1, \mathrm{CI}: 1.23,3.83)$ more likely among women who started their first sexual intercourse before 18 years and women that disclosed to a third-party about having an abortion as compared to their counterparts, respectively (Table 5).

\section{Discussion}

Adjusting for other variables, study participants who did not understand their fertility cycle and when they were most likely to conceive after menstruation, having an abortion procedure previously with medication abortion, having multiple sexual partners in the past 12 months, perceiving that the abortion procedure was not painful, initiating sexual intercourse before the age of 18 years and disclosing about terminating the pregnancy to a thirdparty were independent predictors of repeat abortion.

Even though the mean age distribution of study participants was relatively similar, there were differences in socio-demographic characteristics. Controls were slightly more educated. Cases were more likely to be housewives (32.4\%) and controls more likely to be students (42.6\%). Seventy-nine percent (79\%) of cases had their sexual debut at less than 18 years of age compared to $57 \%$ of controls. Cases were also approximately twice as likely to have had multiple sexual partners.

Another study suggests that the prevalence of repeated abortion is high in Ethiopia and that most women seeking repeat abortion do so to financial reasons as well as the desire to stop having children [19]. Our study revealed that rape, unplanned sex and incest were among the leading reasons women sought abortions. The $\mathrm{Na}$ tional Technical and Procedural Guideline for Safe Abortion permits termination of pregnancy in cases of pregnancy resulting from incest or rape when continuation of the pregnancy endangers the life of the 
Table 3 Abortion related characteristics of the respondents, Tigray region, 2015

\begin{tabular}{|c|c|c|c|c|}
\hline \multirow[t]{2}{*}{ Variables } & Controls & Cases & Total & \multirow[t]{2}{*}{$P$-Value } \\
\hline & $N(\%)$ & $N(\%)$ & $N(\%)$ & \\
\hline \multicolumn{5}{|l|}{ Reason for abortion } \\
\hline Family planning is not effective & $12(5.9)$ & $18(17.1)$ & $30(9.9)$ & \multirow[t]{5}{*}{$<0.01$} \\
\hline Unplanned sex & $41(20.1)$ & $16(15.2)$ & $57(18.4)$ & \\
\hline Rape & $86(42.2)$ & $25(23.8)$ & $111(35.9)$ & \\
\hline Pregnancy from family & $29(14.2)$ & $14(13.3)$ & $43(13.9)$ & \\
\hline Others & $36(17.6)$ & $32(30.5)$ & $68(22.0)$ & \\
\hline \multicolumn{5}{|l|}{ Abortion was done using } \\
\hline Medical abortion & $44(21.6)$ & $50(47.6)$ & $94(30.4)$ & \multirow[t]{2}{*}{$<0.01$} \\
\hline MVA or curettage & $160(78.4)$ & $55(52.4)$ & $215(69.6)$ & \\
\hline \multicolumn{5}{|l|}{ Abortion procedure was painful } \\
\hline Yes & $112(54.9)$ & $32(30.5)$ & $144(46.6)$ & \multirow[t]{2}{*}{$<0.01$} \\
\hline No & $92(45.1)$ & $73(69.5)$ & $165(53.4)$ & \\
\hline \multicolumn{5}{|l|}{ Did you get counseling about FP } \\
\hline Yes & $175(85.8)$ & $91(86.7)$ & $266(86.1)$ & \multirow[t]{2}{*}{0.08} \\
\hline No & $29(14.2)$ & $14(13.3)$ & $43(13.9)$ & \\
\hline \multicolumn{5}{|c|}{ Did you get counseling when fertility is return after the procedure } \\
\hline Yes & $159(77.9)$ & $86(81.9)$ & $245(79.3)$ & \multirow[t]{2}{*}{0.20} \\
\hline No & $45(22.1)$ & $19(18.1)$ & $64(23.0)$ & \\
\hline \multicolumn{5}{|l|}{ When it return fertility } \\
\hline Within 2 weeks & $74(46.5)$ & $32(37.2)$ & $106(43.3)$ & \multirow[t]{2}{*}{0.24} \\
\hline Two weeks and above & $85(53.5)$ & $54(62.8)$ & $139(56.7)$ & \\
\hline \multicolumn{5}{|c|}{ Did you face complication while you were pregnant } \\
\hline Yes & $43(21.1)$ & $31(29.5)$ & $74(23.9)$ & \multirow[t]{2}{*}{0.24} \\
\hline No & $161(78.9)$ & $74(70.5)$ & $235(76.1)$ & \\
\hline \multicolumn{5}{|l|}{ Type of complication } \\
\hline Bleeding & $32(74.4)$ & $25(80.6)$ & $57(77)$ & \multirow[t]{3}{*}{0.50} \\
\hline Mechanical trauma & $5(11.6)$ & $5(16.1)$ & $10(13.5)$ & \\
\hline Infection & $6(14)$ & $1(3.2)$ & $7(9.5)$ & \\
\hline \multicolumn{5}{|l|}{ Did you face psychological problem } \\
\hline Yes & $56(27.5)$ & $30(28.6)$ & $86(27.8)$ & \multirow[t]{2}{*}{0.73} \\
\hline No & $148(72.5)$ & $75(71.4)$ & $223(72.2)$ & \\
\hline \multicolumn{5}{|l|}{ Did you disclosure to any one } \\
\hline Yes & $90(44.1)$ & $61(58.1)$ & $151(48.9)$ & \multirow[t]{2}{*}{0.02} \\
\hline No & $114(55.9)$ & $44(41.9)$ & $158(51.1)$ & \\
\hline \multicolumn{5}{|l|}{ To whom did you disclose } \\
\hline Partner & $19(21.1)$ & $19(31.1)$ & $38(25.2)$ & \multirow[t]{3}{*}{0.45} \\
\hline Family & $25(27.8)$ & $15(24.6)$ & $40(26.5)$ & \\
\hline Friend & $46(51.1)$ & $27(44.3)$ & $73(48.3)$ & \\
\hline
\end{tabular}

mother, the fetus has an incurable and serious deformity, and the pregnant woman has a physical or mental deficiency [8]. It's possible that women are increasingly aware of the laws governing abortion in Ethiopia, particularly as related to rape and incest, and that they are choosing to have procedures at public facilities at little or no cost.

A study in Addis Ababa found that $69.1 \%$ of postabortion patients had ever used contraceptives and majority of these ever used injectables [18]. This is 
Table 4 Health related characteristics of the respondents, Tigray region, 2015

\begin{tabular}{lllll}
\hline Variables & Controls & Cases & Total & P-Value \\
& $N(\%)$ & $N(\%)$ & $N(\%)$ & \\
\hline
\end{tabular}

Have you ever use FP

$\begin{array}{lllll}\text { Yes } & 138(67.6) & 72(68.6) & 210(68.2) & 0.86 \\ \text { No } & 66(32.4) & 33(31.4) & 99(32.0) & \end{array}$

Type of FP

$\begin{array}{llll}\text { Injectable } & 82(59.4) & 52(72.2) & 134(63.8) \\ \text { Pill } & 41(29.7) & 10(13.9) & 51(24.3) \\ \text { Implanon } & 9(6.5) & 4(5.6) & 13(6.2) \\ \text { IUCD } & 1(0.7) & - & 1(0.5) \\ \text { condom } & 5(3.6) & 6(8.3) & 11(5.2)\end{array}$

Have you ever use emergency contraceptive (EC)

$\begin{array}{llll}\text { Yes } & 44(38.3) & 26(43.3) & 70(40.0) \\ \text { No } & 71(61.7) & 34(56.7) & 105(60.0)\end{array}$

After what time did you use EC

$\begin{array}{llll}\text { Within } 1 \text { day } & 10(22.7) & 13(50) & 23(32.9) \\ \text { After } 1 \text { day } & 14(31.8) & 2(7.7) & 16(22.9) \\ \text { After } 2 \text { day } & 15(34.1) & 3(11.5) & 18(25.7) \\ \text { After } 3 \text { day } & 5(11.4) & 8(30.8) & 13(18.6)\end{array}$

Did you have plan to use FP for the future

$\begin{array}{llll}\text { Yes } & 184(90.2) & 89(84.8) & 273(88.3) \\ \text { No } & 20(9.8) & 16(15.2) & 36(11.7)\end{array}$

Did you know when the fertility is return after manustration

$\begin{array}{llll}\text { Yes } & 140(68.6) & 56(53.3) & 196(63.4) \\ \text { No } & 64(31.4) & 49(46.7) & 113(36.6)\end{array}$

When to return fertility after manustration

$\begin{array}{llll}1-8 \text { days } & 45(32.1) & 6(10.7) & 51(26) \\ \text { 9-18 days } & 84(60.0) & 46(82.1) & 130(66.3) \\ \text { After 18 days } & 11(7.9) & 4(7.1) & 15(7.7)\end{array}$

Regularity of the manustration

$\begin{array}{llll}\text { Regular } & 129(63.2) & 63(60.0) & 192(62.1) \\ \text { Irregular } & 67(32.8) & 38(36.2) & 105(34.0) \\ \text { I do no } & 8(3.9) & 4(3.8) & 12(3.9)\end{array}$

Having a repeated abortion can result in abortion

\begin{tabular}{lllll} 
Agree & $129(63.2)$ & $63(60)$ & $192(62.1)$ & 0.04 \\
I do no & $67(32.8)$ & $38(36.2)$ & $105(34.0)$ & \\
Disagree & $8(3.9)$ & $4(3.8)$ & $12(39.0)$ \\
\hline
\end{tabular}

consistent with the findings in our study. More than twothirds of cases and controls had ever used contraceptives and injectable contraceptive was the most common contraceptive ever used. A study of post-abortion care (PAC) in public health facilities of Ethiopia indicated that only two in ten women asked for contraceptives during post-abortion care (PAC) visits and providers offered information on contraception to approximately half of all women [20].
Table 5 Predictors of repeated abortion, Tigray region, 2015

\begin{tabular}{|c|c|c|c|c|}
\hline \multirow[t]{3}{*}{ Variables } & \multicolumn{2}{|l|}{ Abortion } & \multirow[t]{3}{*}{ COR [95\%] } & \multirow[t]{3}{*}{ AOR [95\%] } \\
\hline & Repeated & Single & & \\
\hline & $N(\%)$ & $N(\%)$ & & \\
\hline \multicolumn{5}{|c|}{ Know when to return fertility after menstruation } \\
\hline Yes & $56(53.3)$ & $140(68.6)$ & 1 & 1 \\
\hline No & $49(46.7)$ & $64(31.4)$ & $1.9(1.17,3.1)$ & $2.0(1.12,3.69)$ \\
\hline \multicolumn{5}{|l|}{ Abortion done } \\
\hline Medical abortion & $50(47.6)$ & $44(21.6)$ & $3.3(1.98,5.49)$ & $3.3(1.83,6.11)$ \\
\hline Surgical abortion & $55(52.4)$ & $160(78.4)$ & 1 & 1 \\
\hline \multicolumn{5}{|c|}{ Perceive that the abortion procedure was painful } \\
\hline Yes & $32(30.5)$ & $112(54.9)$ & 1 & 1 \\
\hline No & $73(69.5)$ & $92(45.1)$ & $2.7(1.68,4.57)$ & $2.3(1.31,4.26)$ \\
\hline \multicolumn{5}{|c|}{ Age at first sexual intercourse } \\
\hline Less than 18 & $83(79)$ & $117(57.4)$ & $2.8(1.62,4.84)$ & $2.7(1.49,5.23)$ \\
\hline 18 and above & $22(21)$ & $87(42.6)$ & 1 & 1 \\
\hline \multicolumn{5}{|c|}{ Sexual partner in the past 12 months } \\
\hline One & $29(27.6)$ & $109(53.4)$ & 1 & 1 \\
\hline Two and above & $76(72.4)$ & $95(46.6)$ & $2.9(1.74,4.94)$ & $4.4(2.39,8.45)$ \\
\hline \multicolumn{5}{|l|}{ Abortion disclosure } \\
\hline Yes & $61(58.1)$ & $90(44.1)$ & $1.7(1.09,2.82)$ & $2.1(1.23,3.83)$ \\
\hline No & $44(41.9)$ & $114(55.9)$ & 1 & 1 \\
\hline \multicolumn{5}{|c|}{ Repeated abortion results in sterility } \\
\hline Agree & $63(60)$ & $129(63.2)$ & $0.2(0.09,0.78)$ & $0.3(0.1,12)$ \\
\hline I do no & $38(36.2)$ & $67(32.8)$ & $0.3(0.1,1.02)$ & $0.4(0.11,1.45)$ \\
\hline Disagree & $4(3.8)$ & $8(3.9)$ & 1 & 1 \\
\hline
\end{tabular}

Our study showed that more than $80 \%$ of cases and controls intend to use family planning in the future, although one-third does not know when their fertility resumes after having an abortion. A study in Kano, Nigeria, showed that in $13 \%$ of observed cases, the provider did not explain that the patient had an immediate risk of repeat pregnancy if she did not use contraception following an abortion [21]. This may indicate that Ethiopia is missing an important opportunity to provide contraceptive to women who are likely to need family planning. PAC providers should offer information about family planning, including side-effects, method mix and effective period, to help PAC patients avoid future abortions. A study in Bolivia showed $97 \%$ of PAC patients were counseled about family planning after improved PAC services were introduced [22], which could be a model for a similar initiative in Ethiopia.

Different studies show that abortion increase the risk of complications, namely: placenta previa, which increases the risk of fetal malformation, perinatal death and excessive bleeding during labor [23]. Multiple abortions have been found to correlate with poor health [11]. This is somewhat in line with our findings. Our study showed 
that a considerable percentage of cases had complications while they were pregnant and that most complications were from bleeding, mechanical-related issues, trauma and infection.

For most couples, an abortion causes unforeseen problems in the relationship. Post-abortion couples are more likely to divorce or separate. After an abortion, many women develop a greater difficulty forming lasting bonds with a male partner [24]. In our study, approximately three out of ten women had psychological problems associated with the abortion, including lowered self-esteem, greater distrust of men and sexual dysfunction. However, marital status was not a significant determinant of repeat abortion in our study.

Eight of ten women in our study initiated sexual intercourse before the age of 18 years. Different studies show there's a strong correlation between the earlier sexual debut and abortion [25]. In our study, women who started sexual intercourse before the age of 18 had odds three times higher of being a case than those who started at 18 or later. The Government should work to help adolescents delay sexual debut as well as encouraging family planning, including by empowering communities and particularly women, to freely discuss sexuality with young girls at home.

The number of sexual partners a woman has also tied to higher rates of repeat abortion. Studies show that 40 - $50 \%$ of women who have had 10 or more (male) lifetime sexual partners have had an abortion [26] and almost $90 \%$ of women who have had at least one abortion have had three or more sexual partners [27]. This is in line with our findings, which showed the odds of repeated abortion were four times higher among women who had two or more sexual partners as compared with those who had one sexual partner. The Government should continue to encourage women to limit and reduce their number of sexual partners, both as a way to reduce HIV and STI transmission, but also as a means of preventing abortion.

Our study showed women who used medication for the current abortion were more likely to have had repeated abortions than those who had a surgical abortion. Given that medical abortion seems natural, with no shots, anesthesia, instruments or vacuum aspirator, and allows the woman to be at home instead of in a clinic, this method of abortion may seem more comforting, private and low-risk to women [28, 29]. Even though medical abortion has several advantages, it fails more often than surgical abortion, requires at least two visits, and entails longer cramping and bleeding than occurs after a surgical abortion.

The odds of repeated abortion among women who disclosed to a third-party about terminating the pregnancy were two times as high as those women that did not disclose to a third-party. This implies that disclosing the procedure may provide women the psychological or financial support needed to carry out the procedure.

Even though, our study tried to identify determinant factors of repeat abortion among women seeking abortion care, it was limited by the fact that identifying women who had previous abortions in other health facilities were challenging due to the sensitivity of the subject, although our study endeavored to take a detailed history whether the woman had repeat abortions or not. Moreover, although rape and incest combined were identified by $40 \%$ of cases and $55 \%$ of controls as the reason for seeking an abortion, we were not able to validate these seemingly high rates through external sources like police records. Given that the law in Ethiopia permits abortion in the case of rape and incest, it is worth exploring to see if these high rates of reported rape and incest represent the complete picture. Finally, selecting cases consecutively may not give equal chance for the women to be enrolled in our study.

\section{Conclusions}

This study identified several factors correlated with women having repeat abortions in Tigray, Ethiopia. It may be helpful if the Government of Ethiopia encourages women to delay sexual debut and decrease their number of sexual partners, including by promoting discussion within families about sexuality, to decrease the occurrence of repeated abortion.

\section{Abbreviation \\ AOR: Adjusted odd ratio; Cl: Confidence interval; COR: Crude odd ratio; EDHS: Ethiopian demographic health survey; Max: Maximum; MIN: Minimum; MVA: Manual vacuum aspiration; PAC: Post abortion care; SD: Standard deviation; SPSS: Statistical package for social sciences; VIF: Variance inflation factor}

\section{Acknowledgements}

The authors would like to thank Mekelle University, College of Health Sciences for supporting us financial support in conducting this research. Our gratitude also goes to supervisors, data collectors, respondents, Tigray regional health bureau and public hospital of the region administrative for facilitating the study.

\section{Funding}

The research got a grant from Mekelle University, College of Health Sciences. However, the granting agency has not a role in the design of the study and collection, analysis and interpretation of data and in writing the manuscript. And they simply need the final report which is submitted by the research team.

Availability of data and materials

Our data will not be shared in order to protect the participants' anonymity

\section{Authors' contributions}

MA and HY: initiation of the study, design, analysis and writing of the manuscript. MA, HY AAM, AB, MF and GG: assisted in the design, participated in organizing of the data collection process and writing the manuscript. All authors read and approved the final manuscript and have equal contribution. 


\section{Competing interests}

The authors declare that they have no any competing interests.

\section{Consent for publication}

Not applicable.

\section{Ethics approval and consent to participate}

The study protocol was approved by the Institutional Research Review Board of Mekelle University College of Health Sciences and Community Services Ethical Review Committee. Permission was obtained from all relevant authorities in the Tigray Regional Health Bureau as well as participating hospitals. Written consent was obtained from participants prior to enrollment in the study. Besides, parental/guardian consent was waived to include the minors to the study by the ethical board. Participation in the study was voluntary and participants were informed of the right to withdraw from the study. Data collection was conducted confidentially and data was de-identified and de-linked and stored in a secure location.

\section{Author details}

${ }^{1}$ School of Public Health, Mekelle University, College of Health Sciences, Mekelle, Ethiopia. ${ }^{2}$ School of Public Health, Addis Ababa University, Addis Ababa, Ethiopia. ${ }^{3}$ Department of Obstetrics and Gynecology, University of Illinois at Chicago, Chicago, USA.

\section{Received: 2 March 2016 Accepted: 3 February 2017} Published online: 13 February 2017

\section{References}

1. WHO. Global and regional estimates of the incidence of unsafe abortion and associated mortality in 2008. Geneva: WHO; 2008.

2. Dabash R, Roudi-Fahimi F. Abortion in the Middle East and North Africa. 2008. Population reference bureau.

3. Belton S, Whittaker A, Barclay L. Maternal mortality, unplanned pregnancy and unsafe abortion in Timor-Leste:asituational analysis. 2009. Alola and United Nations Population Fund.

4. Mesce D. Unsafe abortion: facts \& figures. Washington: Population reference bureau; 2005.

5. Frank M, FRCGP, Kay CR, Wingrave SJ, Osborne J. Induced abortion operations and their early sequelae. J R Coll Gen Pract. 1985;35:175-80.

6. Grimes and Cates. Abortion: Methods and complications. Hum Reprod. 1986;796-813.

7. Abdel-Tawab N. Challenges and opportunities in providing post abortion family planning services. In: International union for the scientific study of family planning. 26th ed. Morocco: IUSSP; 2009.

8. FMOH. Technical and Procedural Guidelines for Safe Abortion Services in Ethiopia. Addis Ababa: Federal Democratic Republic of Ethiopian Minster of Health; 2006.

9. Vélez LF, et al. The role of health systems and policy in producing behavior and social change to enhance child survival and development in low- and middle-income countries: an examination of the evidence. J Health Commun. 2014;19(1):89-121.

10. Dgedge M, Gebreselassie H, Bique C. Confronting maternal mortality: The status of abortion care in public health facilities in Mozambique. 2005

11. Ney P, et al. The effects of pregnancy loss on women's health. Soc Sci Med. 1994;38(9):1193-200.

12. Swingle $\mathrm{H}$, et al. Abortion and the risk of subsequent preterm birth: a systematic review with meta-analyses. J Reprod Med. 2009;54:95-108.

13. Addor V, Narring F, Michaud P. Abortion trends 1990-1999 in a Swiss region and determinants of abortion recurrence. Swiss Med Wkly. 2003;133:219-26.

14. Prata N, et al. Contraceptive use among women seeking repeat abortion in Addis Ababa, Ethiopia. Afr J Reprod Health. 2013;17(4):56-65.

15. TRHB. Tigray Regional Health Bureau 2006 EFY Annual Profile. Mekelle: Federal Democratic Republic of Ethiopian Minster of Health; 2006.

16. Central Statistical Agency (Ethiopia) and ORC Macro. Ethiopia Demographic and Health Survey 2011. Addis Ababa and Calverton, MD: Central Statistical Agency and ORC Macro. 2012.

17. Kozinszky Z, et al. a Predictive model of repeat induced abortion in Hungary. Cent Eur J Med. 2011;6(6):701-9.

18. Melkamu Y, Enquselassie F. Fertility awareness and post-abortion pregnancy intention in Addis Ababa, Ethiopia. Ethiop J Health Dev. 2003;17(3):167-74.
19. Bekele H. Assessment of factors associated with HIV among women seeking post-abortion care in public hospitals of Addis Ababa, Ethiopia. 2007.

20. Kumbi S, Melkamu Y, Yeneneh H. Quality of post-abortion care in public health facilities in Ethiopia. Ethiop J Health Dev. 2008;22(1):26-33.

21. Fetters T, Akiode A, Oji E. Putting quality first: an assessment of postabortion care services at Murtala Muhammad specialist hospital in Kano, Nigeria. Chapel Hill: Ipas; 2004

22. Gonzales F, Loayza M. Operations research to improve postabortion care services in three public hospitals, Bolivia. Washington: The Population Council in collaboration with Pathfinder International and the CATALYSTConsortium; 2005

23. Barrett J, Boehm F, Killam A. Induced abortion: a risk factor for placenta previa. Am J Obstet Gynecol. 1981;141:769-72.

24. Berger C, Gold D, Andres D. Repeat abortion: is it a problem? Fam Plann Perspect. 1984;16:70-5.

25. Starr P. Contraceptive use, multiple partners linked to higher rate of abortion. 2014. http://www.cnsnews.com/news/article/penny-starr/study-contraceptiveuse-multiple-partners-linked-higher-rate-abortion. Accessed Jan 2015.

26. Starr P. Contraceptive use, multiple partners linked to higher rate of abortion. Washington: Family Research Council (FRC); 2015.

27. Fagan $P$, Talkington S. Multiple sex partners, broken homes lead to more abortions. Washington: Family Research Council's Marriage and Religion Research Institute (MARRI); 2014.

28. Cappiello J, Merrell J, Rentschler D. Women's experience of decision-making with medication abortion. J Matern Child Nurs. 2014;39:325-30.

29. Swica Y, Chong E, Middleton T. Acceptability of home use of mifepristone for medical abortion. Contraception. 2013;88:122-7.

\section{Submit your next manuscript to BioMed Central and we will help you at every step:}

- We accept pre-submission inquiries

- Our selector tool helps you to find the most relevant journal

- We provide round the clock customer support

- Convenient online submission

- Thorough peer review

- Inclusion in PubMed and all major indexing services

- Maximum visibility for your research

Submit your manuscript at www.biomedcentral.com/submit 